\title{
Projeto de cadeia de suprimentos ágeis e verdes: estudos exploratórios em uma empresa de bens de consumo não duráveis
}

\author{
Angelica Reis Galdino Takahashia, Luis Antonio de Santa-Eulalia ${ }^{\mathrm{b}^{*}}$, Gilberto Miller Dévos Ganga, \\ Juliano Bezerra de Araujo ${ }^{\text {a }}$ Rodrigo Cambiaghi Azevedo ${ }^{\mathrm{d}}$ \\ ${ }^{a}$ Ernst \& Young Assessoria Empresarial Ltda, São Paulo, SP, Brasil \\ b* Université de Sherbrooke, Faculté d'administration, Sherbrooke, Canadá, L.Santa-Eulalia@usherbrooke.ca \\ 'Universidade Federal de São Carlos, São Carlos, SP, Brasil \\ ${ }^{\mathrm{d}}$ Ernst \& Young LLP, Atlanta, United States of America
}

\begin{abstract}
Resumo
Novas tendências em gestão da cadeia de suprimentos têm fomentado grandes discussões na área, incluindo os paradigmas de alinhamento dinâmico e de gestão sustentável de cadeias. 0 primeiro prega que se deve gerenciar dinamicamente diferentes tipologias de cadeias (e.g. totalmente flexíveis, ágeis, enxutas e de reabastecimento contínuo) a fim de responder adequadamente a comportamentos específicos dos clientes. 0 segundo preconiza que o projeto e a gestão dessas cadeias devem considerar questões ambientais e sociais, em complementação aos aspectos econômicos. Recentemente, alguns autores têm combinado essas tendências em um novo modelo conceitual visando melhor gerenciar trade-offs de sustentabilidade quando do projeto de cadeias de suprimentos. 0 objetivo deste trabalho é testar algumas das hipóteses levantadas por tal modelo em cadeias 'ágeis'. Por meio de simulações em uma multinacional de bens de consumo não duráveis, foi possível verificar que o modelo proposto possui coerência e potencial para ajudar as empresas a projetar cadeias ágeis e verdes.
\end{abstract}

Palavras-chave

Cadeia de suprimentos. Sustentabilidade. Alinhamento dinâmico. Projeto de redes logísticas. Indústria de bens de consumo não duráveis. Projeto de experimentos Taguchi.

\section{Introdução}

Diversas tendências na área de gestão de cadeia de suprimentos têm mudado a maneira como as comunidades acadêmica e empresarial entendem esse complexo paradigma de gestão. Dentre elas pode-se citar a gestão e alinhamento dinâmicos (Gattorna, 2009, 2006) e a gestão sustentável de cadeias de suprimentos (Dias et al., 2012; Pagell \& Zhaohui, 2009; Svensson, 2007).

Proposta inicialmente por Gattorna (2006), o conceito de gestão e alinhamento dinâmicos preconiza que as empresas devem gerenciar dinamicamente diferentes tipos de cadeias de suprimentos a fim de responder adequadamente a diversos comportamentos de compra dos clientes, dado que estes divergem entre si e possuem necessidades de valor distintas, requerendo respostas diferenciadas por parte das cadeias de suprimentos.

As abordagens tradicionais definem apenas uma estratégia de atendimento para todos os segmentos de clientes (conhecido como "one size fits all"), no lugar de múltiplas possibilidades. É presumível que as empresas obtenham um desempenho superior ao reconhecer tais diferenças, de forma a alinhar a entrega de valor em conformidade com as necessidades dos clientes (Gattorna, 2006).

Em termos práticos, tal conceito implica a definição de estratégias específicas de atendimento para cada grupo de consumidores, incluindo, por exemplo, níveis diferenciados de intensidade de comunicação, abordagens colaborativas, preços, 
estrutura de distribuição, dentre outros aspectos. Nesse contexto, Gattorna (2006) propõe quatro principais tipos de cadeia genéricas para atender a segmentos específicos de clientes: totalmente flexíveis, ágeis, enxuta e de reabastecimento contínuo.

Por outro lado, a gestão sustentável de cadeia de suprimentos preconiza que o projeto e a gestão dessas diferentes categorias de cadeias devem levar em conta inúmeras questões ambientais e sociais em complementação aos clássicos critérios econômicos, ampliando o tradicional paradigma de gestão de cadeias, tanto do ponto de vista dos clientes, como de outros stakeholders (Seuring \& Muller, 2008). Recentemente um movimento global por cadeias mais sustentáveis foi estruturado e recomendando pelas Nações Unidas, em parceria com a organização Business for Social Responsibility (BSR), baseadas nos dez princípios do Pacto Global que deveriam ser incorporados às práticas de gestão de cadeias (UN Global Compact, 2010). Outros trabalhos (Carbon Disclosure Project, 2011; Hutchins \& Sutherland, 2008; Wilkerson, 2008) também visam discutir como identificar e implementar melhores práticas e indicadores de desempenho para o negócio sustentável. Entretanto, Seuring \& Muller (2008) destacam que, mesmo com a maior atenção dada a esse assunto, muitos esforços ainda são necessários para transformar tal abordagem em um conceito difundido e aceito.

Estudos correlatos, desenvolvidos por SantaEulalia et al. (2009, 2010), propõem um modelo conceitual inovador combinando essas duas novas tendências com o objetivo de auxiliar as empresas a melhor gerenciar os trade-offs de sustentabilidade ambiental em projeto de cadeias de suprimentos dinâmicas. Os autores debatem de que forma o projeto de redes logísticas poderia conjugar aspectos de alinhamento dinâmico da cadeia a partir de uma perspectiva de gestão verde. 0 constructo conceitual destes trabalhos baseou-se em critérios clássicos de projeto de redes logísticas e nas tipologias de cadeias propostas por Gattorna (2006), a fim de entender e posicionar como tais cadeias respondem aos atributos de desempenho verdes, tais como reduções de emissões, de consumo de energia, de materiais e de resíduos. Acredita-se fortemente que essa seja uma importante lacuna na literatura acadêmica e profissional.

0 cenário destacado suscitou o desenvolvimento deste trabalho, ou seja, levantar indícios empíricos de que alguns pressupostos levantados pelo modelo conceitual de Santa-Eulalia et al. (2009, 2010) possam ser válidos para o setor de bens de consumo não duráveis em cadeias ágeis. Nesse sentido, o artigo faz uso de uma pesquisa exploratória (Silva \& Meneses, 2005) com método de pesquisa experimental (Bryman, 1989), via a abordagem de plano de experimentos de Taguchi (Taguchi, 1986). Os experimentos de simulação foram realizados a partir de dados empíricos de uma multinacional sul-americana na área de bens de consumo não duráveis. Para tanto, foi adotada a seguinte hipótese para esta pesquisa:

Existem indícios empíricos de que o modelo conceitual proposto por Santa-Eulália et al. (2009, 2010) seja robusto o suficiente para auxiliar a comunidade acadêmica e empresarial a projetar cadeias de suprimentos ágeis e verdes.

Deve-se salientar que não se pretende obter generalizações para as cadeias ágeis em geral, ou mesmo para o setor industrial em estudo. Trata-se de um estudo exploratório e deseja-se apenas levantar indícios de validade do modelo de Santa-Eulalia e colegas para o caso em questão. Generalizações poderão ser obtidas em trabalhos futuros, quando diversas empresas do setor serão estudadas, conforme explicado ao final desse manuscrito.

Para compreender as análises e simulações experimentais propostas, o trabalho foi estruturado em três partes. A seção 2 lança as bases teóricas da discussão central, incluindo os modelos conceituais de Gattorna (2006, 2009) e de Santa-Eulalia et al. (2009, 2010). A seção 3 apresenta a metodologia de pesquisa empregada neste trabalho, bem como discute os resultados experimentais com vias a testar algumas das hipóteses do modelo de Santa-Eulalia e colegas. Finalmente, a seção 4 apresenta alguns comentários finais, conclusões e discute possíveis trabalhos futuros.

\section{Fundamentação teórica}

\subsection{Alinhamento dinâmico de cadeias de suprimentos}

Baseado em sua experiência como consultor, executivo, pesquisador e professor, John Gattorna (Gattorna, 2009, 2006) propôs um modelo conceitual fundamentado em casos reais, preconizando a gestão e o alinhamento dinâmicos das cadeias de suprimentos múltiplas, orientados segundo os comportamentos mercadológicos. Fundamentalmente, tal modelo enfatiza que as empresas de sucesso são aquelas cuja estratégia, traduzida em uma proposta de valor, está alinhada com os perfis de compra dos clientes. Este alinhamento ocorre à medida que 0 estilo de liderança e as capacidades internas (cultura 
organizacional) satisfaçam, por segmentos de clientes, os diferentes atributos valorizados por eles. Para tanto, as empresas devem alinhar os processos de negócio e a infraestrutura tecnológica para garantir formatos distintos de operação, de acordo com o grupo de cliente servido, cada qual sendo atendido pela forma que mais valoriza.

Baseado nos estudos do psicanalista Carl Gustav Jung, Gattorna (2006) propôs uma segmentação composta de quatro tipos genéricos de clientes, sendo eles: Empreendedores, Produtores, Administradores e Integradores. Desta forma, ao afirmar que o principal ingrediente das cadeias são as pessoas, Gattorna (2006) agrupa esses tipos comportamentais em quatro comportamentos de compra diferentes, gerando quatro tipos de cadeias de suprimentos também diferentes, as quais são alinhadas com os clássicos perfis de Jung, a saber: cadeia totalmente flexível, ágil, enxuta e de reabastecimento contínuo. Assim, a cada segmento de cliente deve estar associado um tipo de cadeia de suprimentos mais adequada para a entrega do valor proposto. Os tipos genéricos de cadeias e suas respectivas propostas de valor estão resumidos na Figura 1.

0 primeiro tipo é a cadeia totalmente flexível. Essas cadeias estão associadas a alto custo, projetadas para solucionar problemas imprevistos com rapidez. Gattorna (2009) subdivide esse tipo de cadeia em outros dois: a cadeia de valor totalmente flexível para 'evento de negócio' e a cadeia de valor totalmente flexível para 'resposta de emergência/ humanitária'. Como os nomes sugerem, a primeira é encontrada em geral no ambiente empresarial e tem pouca sensibilidade ao custo por se tratar de uma solução para um evento isolado e com fundos substanciais. A segunda se diferencia da primeira pela sua sensibilidade ao custo, já que os fundos destinados a esta cadeia se originam de doações para emergências. A proposta de valor, para ambos os casos acima citados, é "[...] atender a demandas não programadas e não planejáveis com soluções rápidas, eficazes e centradas no consumidor, que geralmente não estariam disponíveis em circunstâncias normais" (Gattorna, 2009, p. 146).

No segundo tipo de cadeias, as ágeis, os clientes são exigentes, fazendo com que o foco da cadeia seja rapidez e inteligência no alinhamento com os clientes. Paralelamente, o desafio para as empresas é saber como satisfazer seus clientes quando estes saem dos ambientes operacionais previsíveis para os imprevisíveis, requerendo a habilidade de prever a capacidade de operação com elevada precisão, de forma a permitir que a produção de alta prioridade tenha benefícios em detrimento de outras em alguns momentos. É importante saber diferenciar quando a demanda é urgente ou não para que se saiba quando é imprescindivel a resposta rápida. Além disso, o atendimento a clientes exigentes está
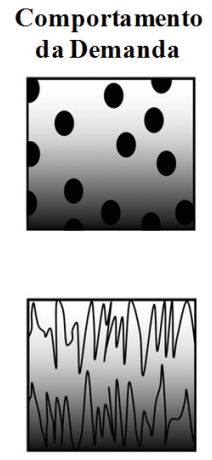

\footnotetext{
Produtores: Resposta rápida

- Rápida resposta a demandas variáveis

- Foco em entregas urgentes

- Baixa fidelidade dos clientes

- Consciente do preço
}

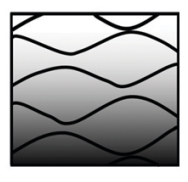

Administradores: Eficiência e consistência - Resposta consciente para demandas previsíveis

- Foco em eficiência

- Sensível ao preço

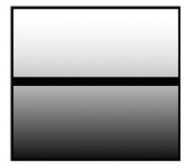

Integradores: Colaboração

- Relações de trabalho próximas

- Demandas mais previsíveis

- Foco no relacionamento

-Fidelidade
Propostas de Valor

Foco na cap acidade de entrega rápida de soluções inovadoras

Foco em responder rapidamente e comercialmente a condições de demandas pouco previsíveis

Foco em economia de escala, sinergia e baixo custo de produção e entrega

Foco no desenvolvimento da fidelidade de clientes com produtos $\mathrm{e}$ serviços confiáveis
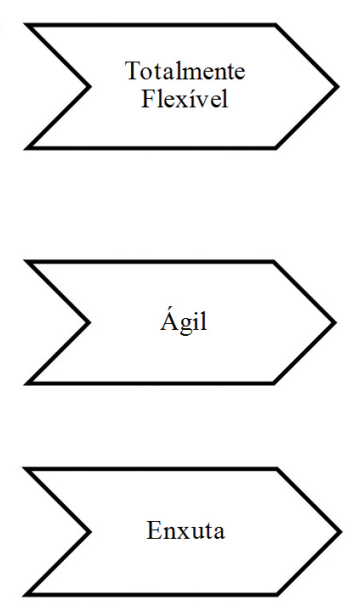

Tipos de Cadeia

.

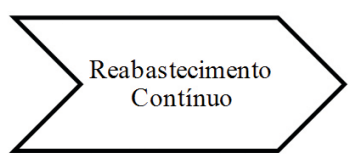

Figura 1. Os quatro tipos genéricos de cadeias de suprimentos, segundo Gattorna. Fonte: adaptado de Gattorna (2009). 
associado a um custo incremental, que será pago por aqueles que realmente necessitam desses serviços urgentes, caracterizando menor sensibilidade ao preço. Pode-se comparar a atual venda de passagens aéreas a esse tipo de cadeia, uma vez que há a reserva de capacidade para clientes de última hora. Os passageiros que optam por realizar a compra com pequena antecedência em relação à data do voo, têm um custo superior ao dos clientes que compraram as passagens anteriormente, evidenciando o trade-off custo - antecipação de compra.

0 terceiro tipo é a cadeia de suprimentos enxuta. Essa cadeia se caracteriza por ter baixos custos (como sugere o nome "enxuto"), os quais são atingidos por meio de processos básicos e bem executados. 0 desejo do mercado é pela eficiência/consistência, que leva a expectativas em relação a preço e previsibilidade, com estabilidade da demanda. Clientes desse mercado comparam preços, sem desenvolver lealdade, e, por isso, a informação é estratégica, de forma que não há compartilhamento entre compradores e vendedores. Esses clientes oferecem poucas oportunidades aos fornecedores de se diferenciarem na proposição de valor, de forma que o valor é um serviço confiável, em que o cliente sabe o que vai receber. Ao considerar as características desse tipo de cadeia, pode-se afirmar que a estrutura de compra de commodities se encaixa na descrição acima e pode ser considerada como cadeia de valor enxuta.

0 quarto tipo de cadeia de valor trata da cadeia de suprimentos de reabastecimento contínuo. A característica mais específica dessa cadeia é o comportamento de compra verdadeiramente colaborativo dos clientes, que são responsáveis por puxar a cadeia. Nesse tipo de cadeia, o comportamento de compra é previsível e a demanda geralmente se dá por produtos maduros e entregas regulares. A confiança é prioritária no relacionamento, sendo que há compartilhamento de informações entre os membros dessas mesmas cadeias, em busca de aperfeiçoamento de desempenho. Outros fatores que devem ser ressaltados são aqueles em que os clientes colaborativos não são tão sensíveis aos preços, e em que o custo de servi-los é relativamente baixo, devido à estabilidade na demanda apresentada anteriormente. 0 comportamento de compra apresentado pelas montadoras de veículos se aproxima desse tipo de cadeia, pois enviam a seus fornecedores previsões de compras, e têm contratos nos quais a estabilidade de compra é consolidada. Dessa forma, os fornecedores podem se programar para atender constantemente à demanda das montadoras, não somente em quantidade, mas também em pontualidade e qualidade.
Em suma, essa noção de alinhamento de cadeias de suprimentos enfatiza o dinamismo e abrange a empresa de forma global, caracterizando-se como um conceito orgânico, em oposição ao estático. Isso implica se ajustar às alterações dos mercados, ligando mercado e estratégia com a habilidade cultural interna e estilos de liderança na empresa.

$\mathrm{Na}$ subseção seguinte, será discutido como esses conceitos podem ser combinados a uma nova tendência na área, a gestão sustentável de cadeia de suprimentos.

\subsection{Projeto de cadeias de suprimentos dinâmicas verdes}

Como mais uma tendência na área de gestão de cadeias de suprimentos, o tema sustentabilidade tem causado grande impacto. A gestão sustentável de cadeias de suprimentos refere-se às ações específicas de gestão que são tomadas com o objetivo de tornar a cadeia de suprimentos mais sustentável, tal como proposto pelo modelo do resultado triplo, ou triple bottom line (Elkington, 1998). Com esse intuito, os fluxos de materiais, financeiros e de informações devem ser questionados não somente segundo a tradicional ótica de valor econômico, mas também levando em consideração valores ambientais e sociais (Seuring \& Müller, 2008; Pagell \& Zhaohui, 2009; Svensson, 2007).

Quando o conceito de sustentabilidade é restrito apenas às questões ambientais, deixando de lado os aspectos sociais, tem-se o que a literatura define como Gestão Verde de Cadeias de Suprimentos (ou Green Supply Chain Management, como o termo ficou conhecido em inglês). Hervani et al. (2005) define esse conceito como sendo o gerenciamento da cadeia de valor calcado na consciência ambiental, incluindo práticas de negócio como compra levando em conta princípios verdes, produção ou gerenciamento de materiais ambientalmente corretos, rotulagem ambiental e logística reversa. Dessa forma, a ideia é diminuir ou eliminar os impactos negativos causados pela cadeia de suprimentos, como consumo de energia, emissões e resíduos sólidos, dentre outros.

Um aspecto com muito potencial na literatura refere-se ao projeto (ou concepção) de cadeias de suprimentos verdes, ou seja, como levar em conta aspectos ambientais quando uma nova rede logística é delineada. A literatura (Klibi et al., 2010; Kettani, 2008; Pacheco \& Siqueira, 2006; Lakhal et al., 2001 ; etc.) apresenta diversos estudos interessantes sobre como estruturar cadeias de suprimentos considerando-se decisões que envolvem aspectos 'tradicionais', como a seleção de parceiros, a 
localização de plantas e armazéns, a definição de capacidade das instalações, a alocação de produtos às instalações e a seleção de modais de transporte, entre outros. Esses estudos demonstram que, ao desenhar e redesenhar as cadeias (ou redes), as empresas são capazes de reduzir custos e leadtimes de entrega expressivamente, visando se estabelecer em mercados atuais e novos, executar planos de investimento de longo prazo, bem como estabelecer parcerias sólidas com clientes e fornecedores. No entanto, poucos são os trabalhos nessa área que levam em conta critérios 'não tradicionais' ligados à ecologia e à sociedade, tal como preconizado pelo paradigma de gestão verde de cadeias de suprimentos. Além disso, há de se ressaltar que a combinação de conceitos de projetos de cadeias verdes com a noção de alinhamento dinâmico é escassa, sendo claramente uma lacuna importante na literatura científica e empresarial da área.

Um trabalho que combina tais aspectos refere-se ao modelo de Santa-Eulalia e colegas (SantaEulalia et al., 2009, 2010), em que se propõe como tratar esses três elementos conjuntamente (i.e., alinhamento dinâmico, projeto de cadeias de suprimentos e gestão verde), segundo critérios (Baglin et al., 2007) de integração da cadeia de suprimentos, abastecimento, economias de escala, tecnologia, e capacidade instalada.

Primeiramente, a integração da cadeia de suprimentos refere-se essencialmente à integração vertical. Os autores propõem que essa integração varia de acordo com as situações extremas de integração vertical (Albuquerque et al., 2011) e outsourcing (Vernalha \& Pires, 2005). A integração vertical extrema representa uma situação em que a empresa controla toda a cadeia, enquanto o outsourcing ocorre quando se faz uso das estratégias de terceirização e outsourcing estratégico com fornecedores por meio da transferência de funções não relacionadas com a competência principal da empresa. Essas situações extremas formam um continuum, sendo que diversos níveis de verticalização existem entre essas duas situações (Figura 2).

\begin{tabular}{ccc}
\hline Integração & Outsourcing & Vertical \\
\hline Abastecimento & Local & Global \\
\hline Economias de Escala & Centralizado & Distribuído \\
\hline Tecnologia & Especializado & $\longrightarrow$ Polivalente \\
\hline Capacidade & Plena & Ociosa
\end{tabular}

Figura 2. Projeto de rede de cadeia de suprimentos e alguns trade-offs verdes. Fonte: adaptado de Santa-Eulalia et al. (2009, 2010).
Em termos de abastecimento, as empresas podem ser aprovisionadas a partir de fornecedores locais (localizados próximo às instalações) ou globais (normalmente encontrados no exterior). Fornecedores locais permitem uma estratégia de aquisição mais rápida e flexível, enquanto que os globais são mais custo-eficientes e menos flexíveis em relação à estratégia de aquisição (o continuum local - global está representado na Figura 2).

Quanto a economias de escala, as empresas podem concentrar todas as suas atividades em uma ou algumas poucas grandes instalações para a obtenção de economias de escala e reduções de custos marginais (centralizado). Por outro lado, pequenas instalações de produção podem ser criadas e espalhadas por todo o mercado, ficando assim mais perto dos clientes (distribuído). De forma similar ao critério anterior, vários graus de economias de escala existem no interior do continuum centralizado - distribuído da Figura 2.

0 quarto critério, a tecnologia, indica que as empresas podem utilizar tecnologias (ou meios) de produção que variam no continuum especializado - polivalente. A especialização também está fortemente associada à eficiência; sendo assim, pode-se crer que instalações especializadas tendem a gerar menos resíduos, consumir relativamente menos materiais por valor agregado, e são mais eficientes em termos de Energia/GEE (Gás de Efeito Estufa) que tecnologias polivalentes. No entanto, estruturas especializadas normalmente não permitem rápidas reações às variações de mercado.

Finalmente, o último critério refere-se à utilização da capacidade, que varia no continuum capacidade plena - capacidade ociosa (Figura 2). 0 uso de capacidade plena para obter maiores graus de eficiência nos processos pode limitar a habilidade em absorver possíveis variações de demanda; já o uso de capacidade ociosa permite absorção de eventuais variações não previstas de demanda, sendo que essas normalmente incorrem em custos adicionais.

Santa-Eulalia et al. (2009) analisam esses cinco critérios (i.e., integração, abastecimento, escala, tecnologia e capacidade) a partir do ponto de vista ambiental, levando-se em consideração especialmente as emissões de GEE (e.g. $\mathrm{CO}_{2}$ ), o uso de materiais (e.g. matérias-primas), o consumo de energia e a geração de resíduos. Como as emissões de GEE e o consumo de energia estão intimamente relacionados (Stokes, 2009), esses dois elementos são considerados em conjunto no modelo dos autores. Assim, o quadro da Figura 3 é proposto.

$\mathrm{Na}$ Figura 3, o sinal $\uparrow$ indica que o aspecto avaliado tem hipoteticamente um impacto positivo. 
Por exemplo, o outsourcing tende a ter um impacto positivo no consumo de energia e na emissão de gases do efeito estufa uma vez que parceiros mais especializados e eficientes são usados na rede, tendendo à otimização da energia utilizada e à diminuição da emissão de GEE se comparado à verticalização. Ao contrário, o sinal $\downarrow$ mostra que 0 aspecto possui hipoteticamente um impacto negativo. Por exemplo, empresas altamente verticalizadas, que gerenciam desde a matéria-prima ao consumo final, tendem a ser menos eficientes em relação à energia e à emissão de GEE. É importante ressaltar que, neste caso, não foi considerado se a verticalização requer mais transporte ou não, pois os elementos da Figura 3 não foram cruzados.

Os autores vão além ao propor um quadro combinando essa discussão com a teoria de Gattorna
(2006) sobre alinhamento dinâmico de cadeias de suprimentos, tal como esquematizado na Figura 4.

Na Figura 4, o critério "aberto" refere-se a uma situação em que é preciso avaliar o caso em uma base individual, não sendo possivel generalizar tais critérios.

A fim de entender tal quadro, é apresentado o caso das cadeias ágeis, já que esse tipo de cadeia será estudado na parte experimental deste artigo, apresentado na próxima seção. Para detalhes sobre as demais cadeias de suprimentos, os leitores podem consultar o trabalho de Santa-Eulalia et al. (2009, 2010). Sendo assim, os autores levantam às seguintes hipóteses para as cadeias ágeis:

- Integração: empresas ágeis tendem a realizar "outsourcing" para a obtenção de flexibilidade visando suportar variações de demanda. Em comparação com a situação flexível, a cadeia

\begin{tabular}{|c|c|c|c|c|c|c|c|}
\hline Indicadores & Energia/GHG & Materiais & Desperdício & Continuun & Energia/GHG & Materiais & Desperdício \\
\hline Integração & & & & Outsourcing $\leftrightarrow$ Verticalizada & & & \\
\hline Abastecimento & & & & Local $\leftrightarrow$ Global & & & \\
\hline Economias de Escala & & & & Centralizada $\leftrightarrow$ Distribuída & & & \\
\hline Tecnologia & & & & Especializada $\leftrightarrow$ Polivalente & & & \\
\hline Capacidade & & & & Plena $\leftrightarrow$ Ociosa & & & \\
\hline
\end{tabular}

Figura 3. Projeto de rede de cadeia de suprimentos e alguns trade-offs verdes. Fonte: adaptado de Santa-Eulalia et al. (2009, 2010).

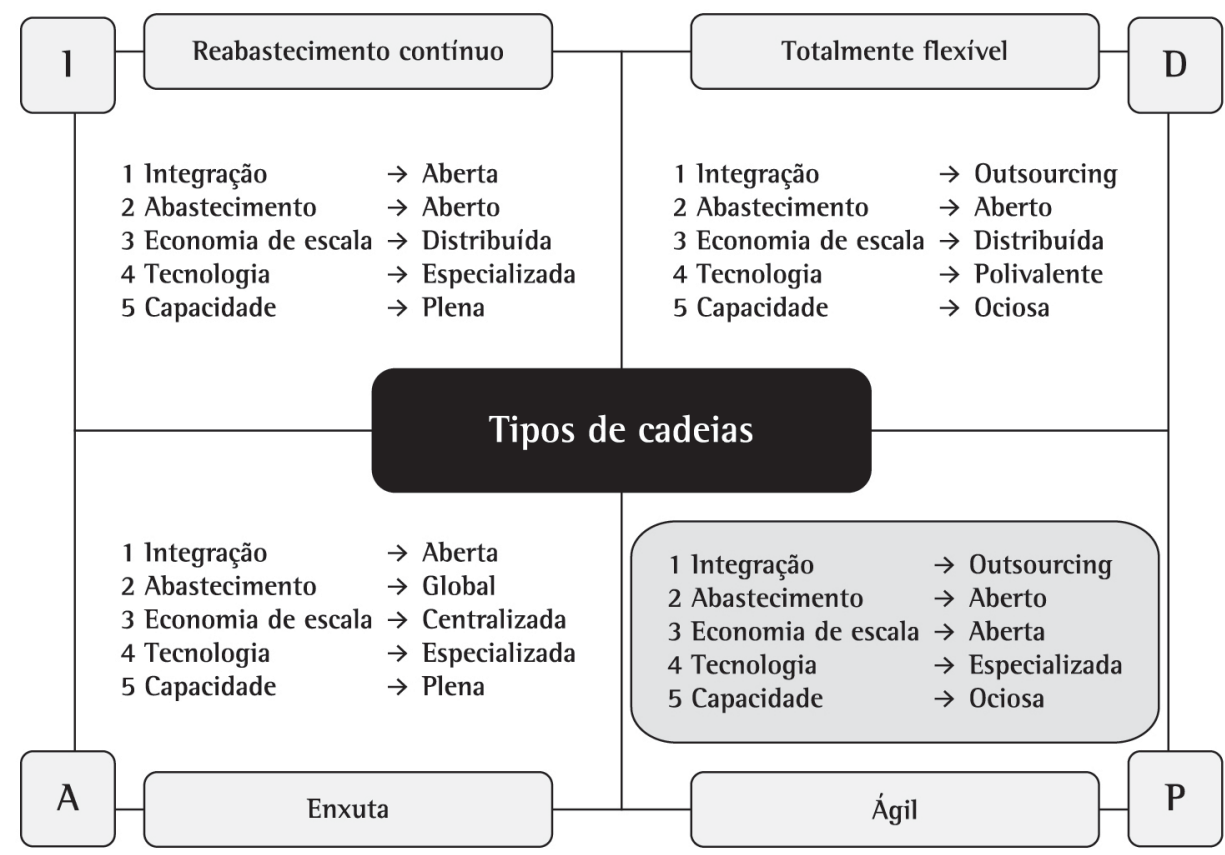

Figura 4. Tipos de Cadeias de Suprimentos e Projeto de Redes Logísticas. Fonte: adaptado de Santa-Eulalia (2009, 2010). 
de suprimentos ágil é uma situação menos radical, mas o outsourcing é ainda uma opção interessante. Um exemplo típico seria a Dell, que emprega outsourcing estrategicamente para respostas mais rápidas do mercado.

- Abastecimento: o tipo "aberto" é provavelmente a situação geral. Por exemplo, em alguns casos, o abastecimento tende a ser "local" para permitir reduções de leadtime de componentes com elevado valor ou de componentes estratégicos. A empresa Dell pode ser considerada um bom exemplo, pois todos os seus principais fornecedores estão localizados perto de suas instalações (menos de $40 \mathrm{~km}$ nos EUA), o que permite uma resposta rápida às alterações na demanda. Às vezes, uma abordagem híbrida ("global" e "local”) é necessária. Nesse caso, a Zara é um exemplo interessante. Nesta situação, os fornecedores de commodities estão localizados na China, devido ao fato de estes proporcionarem preços mais baixos para matérias-primas não críticas. Já os fornecedores para os componentes mais específicos (normalmente relacionados com inovação acelerada), usados em novos produtos, estão próximos à sua planta na Espanha.

- Economia de escala: é, provavelmente, “aberta”. Os exemplos apresentados no último parágrafo também ilustram essa situação. A Zara segue basicamente uma abordagem centralizada, com uma única fábrica na Espanha, enquanto a Dell decidiu localizar suas instalações em todo o mundo, por exemplo, nos EUA, Marrocos, Brasil, Irlanda, Polônia, China, Malásia e Índia. Ambas são conhecidos casos de cadeia ágil, de acordo com Gattorna (2006).

- Tecnologia: deve-se privilegiar tecnologias do tipo "especializadas" em cadeias ágeis, pois as variações de demanda são comuns em termos de volumes, e menor em termos de variedades, se comparado às cadeias flexíveis. No entanto, em diversas situações, principalmente quando o portfólio de produtos da empresa tende a ser grande, tecnologias polivalentes podem ser utilizadas. Ou seja, existe uma pequena tendência para o uso de tecnologias especializadas, mas nem sempre essa tendência se aplica.

- Capacidade: tende a ser "ociosa" para acomodar variações de demanda e picos de demanda. Dessa forma, a capacidade funciona como um amortecedor para as cadeias de suprimentos ágeis, e igualmente para as cadeias flexíveis.

É importante ressaltar que os trabalhos de SantaEulalia et al., de acordo com o ponto de vista dos autores, referem-se a um ensaio. A discussão sobre esses critérios de projeto de rede representa apenas uma tendência, e várias exceções são possíveis.

Os autores concluem o trabalho apresentando um quadro final para analisar alguns possíveis trade-offs verdes para os quatro tipos de cadeia de suprimentos, sugerindo diversos pontos de atenção e pontos críticos ao se projetar cadeias de suprimentos verdes e dinâmicas. Por exemplo, para o caso de cadeias ágeis (foco do presente trabalho), os autores demonstram que se trata de uma situação complexa a ser gerenciada, pois: i) capacidades ociosas são normalmente correlacionadas com desempenho ambiental inferior, destacado como um ponto crítico pelos autores; ii) os pontos ‘abertos' (abastecimento e economias de escala) devem ser gerenciados com cautela, pois, se enfatizado somente o lado econômico, pode-se, em algumas situações, degradar a performance ambiental. Os leitores interessados no quadro conceitual sobre trade-offs ambientais podem consultar os trabalhos originais dos autores.

Visando testar algumas das hipóteses levantadas sobre as cadeias ágeis, a próxima seção apresenta um estudo experimental preliminar realizado junto a uma empresa multinacional latino-americana na área de bens de consumo não duráveis.

\section{Experimentos em uma empresa de bens de consumo: o caso da cadeia ágil}

\subsection{Empresa estudada}

Devido às exigências de confidencialidade, o nome da empresa estudada não pôde ser revelado. Trata-se de uma multinacional que produz bens de consumo não duráveis, localizada na América do Sul. Esta possuía cerca de $22 \%$ da fatia de mercado em 2010 e experimentava um crescimento consistente nos três anos anteriores.

Tal crescimento vinha forçando a empresa a refletir sobre a possibilidade de ampliar sua capacidade produtiva para melhor servir os seus mercados-alvo. Além disso, considerando a proximidade com seus clientes, a empresa também desejava analisar explicitamente diversos aspectos de sustentabilidade relacionados à sua marca, dado que seus consumidores consideravam cada vez mais esses aspectos nas decisões de compra. Também é importante mencionar que a empresa é consciente de que os diversos mercados atendidos atualmente não podem ser servidos da mesma forma, pois seus consumidores possuem comportamentos de compra muito distintos. Desta forma, esperava-se uma nova arquitetura de cadeia de suprimentos, considerando fatores de alinhamento dinâmico de cadeias de valor e de sustentabilidade.

Sendo assim, a empresa colocou à disposição da equipe uma série de dados históricos reais e 
projeções (para os próximos anos) relacionados à demanda, às localizações de clientes e fornecedores, às características dos produtos e dos processos de produção, armazenamento e distribuição, dentre outros.

Parte significativa dos produtos dessa empresa foi classificada como 'ágil' pela equipe do projeto, formada por pesquisadores internacionais e consultores experientes em gestão de cadeia de suprimentos, gestão ambiental e alinhamento dinâmico. A próxima seção detalha como esse estudo foi organizado pela equipe.

\subsection{Método}

0 presente estudo faz uso da pesquisa exploratória combinada com método de pesquisa experimental, via a abordagem de plano de experimentos de Taguchi.

A pesquisa exploratória tem como objetivo "[...] proporcionar maior familiaridade com o problema com vistas a torná-lo explícito ou a construir hipóteses." Envolve, entre outros, análise de exemplos que estimulem a compreensão e pode assumir, em algumas situações, a forma de estudos de casos (Silva \& Meneses, 2005, p. 21).

Nesse sentido, a presente pesquisa utiliza um caso industrial do setor de bens de consumo não duráveis. Visando analisar como fatores levantados pelo modelo proposto por Santa-Eulalia e colegas poderia influenciar o comportamento da empresa em questão, construiu-se um modelo da cadeia de suprimentos da empresa e realizou-se uma série de testes por meio de uma abordagem metodológica do tipo experimental. Essa abordagem delimita uma série de variáveis de estudo capazes de influenciar um objeto, com o intuito de realizar controle sobre elas e de observar os efeitos sobre o objeto estudado (Bryman, 1989). Esse tipo de metodologia é adequado para estudos relacionados à área de gestão de cadeia de suprimentos (Kotzab et al., 2005).

Para o planejamento dos experimentos, foi utilizado o método de Taguchi (1986), recomendado para otimizar a estrutura de fatores de um experimento tendo como foco a robustez do sistema, ou seja, menos sensível a fatores não controláveis. É sabido que as cadeias de suprimentos são sistemas altamente sensíveis às variações de demanda, operações de manufatura e de abastecimento (Davis, 1993). Ao se testar o modelo em questão em ambientes incertos, em que a variabilidade do mundo de negócios está modelada, deseja-se aproximar da realidade do tipo de cadeia sendo estudado. Tal como indicado por Gattorna (2009), cadeias ágeis representam situações em que as demandas são poucos previsíveis (vide Figura 1), sendo necessário a modelização da demanda como variável incerta. Muitos trabalhos quantitativos infelizmente negligenciam a estocacidade de cadeia de suprimentos, notadamente a demanda (Gupta \& Maranas, 2003). Além do mais, se ainda por cima se deseja saber qual seria a situação ótima, aquela considerada a mais robusta a tais variações, deve-se empregar um delineamento de experimentos do tipo "orientado a otimização" a fim de se encontrar a melhor região para a combinação dos fatores do sistema. 0 método de Taguchi propõe um delineamento para essas situações e já foi diversas vezes empregado na área de cadeia de suprimentos com sucesso, visando estudar regiões ótimas, como em Santa-Eulalia et al. (2011), Genin et al. (2007), Shang et al. (2004), dentre outros trabalhos. Shang et al. (2004) explicam que outros métodos orientados a otimização podem ser usados para esses tipos de experimentos (exclusivamente ou combinados com Taguchi), especialmente metodologia conhecida como Response Surface Methodology (RSM). 0 problema de abordagens do tipo RSM é que elas não podem otimizar as variáveis qualitativas, o que limitaria grandemente o presente estudo, já que se deseja estudar esse tipo de variável neste trabalho.

Tal como nos trabalhos de Santa-Eulalia et al. (2011), Genin et al. (2007), e Shang et al. (2004), os resultados do presente estudo não visam a generalização para as cadeias ágeis em geral, ou ainda para o setor industrial em estudo. Enquanto pesquisa exploratória, este trabalho visa apenas levantar indícios de validade do modelo de SantaEulalia e colegas para o caso em questão. Em sendo assim, deseja-se obter maior familiaridade com a cadeia ágil e obter indícios que ajudem a entender o fenômeno proposto por Santa-Eulalia e colegas. Esse seria o ponto inicial que justificaria trabalhos futuros visando obter validações empíricas generalizáveis por meio de métodos como survey, ou outros.

\subsubsection{Etapas, objetivos e hipóteses de pesquisa}

Esse método é basicamente organizado em duas etapas:

1) Projetar os experimentos: Devem ser definidos os fatores controláveis e não controláveis, e as interações entre eles, os indicadores de desempenho do experimento escolhido e as matrizes ortogonais dos experimentos.

2) Coletar e analisar os dados: Executados os experimentos, os indicadores de desempenho são 
coletados, tabulados e analisados por uma versão de Taguchi para a abordagem ANOVA (Analysis of Variance), utilizada para a identificação dos fatores que mais influenciam o comportamento do objeto estudado, bem como para a identificação da existência de interações de primeira ordem entre os fatores e a força delas. Além disso, gráficos específicos de sinal/ruído são utilizados para encontrar a melhor configuração dos fatores. Os procedimentos de Taguchi serão melhor explicados nas próximas seções.

É importante salientar que os dados fornecidos pela empresa foram compilados pela equipe e utilizados para a parametrização de um sistema de otimização de redes logísticas canadense chamado Supply Chain Studio ${ }^{\circledR}$, o qual será descrito mais tarde.

As experiências foram realizadas para produtos classificados como pertencentes à cadeia de suprimentos ágeis, segundo as definições de Gattorna (2009). Além disso, foi possível obter dados relacionados somente à economia de escala, tecnologias e capacidade, sendo que os demais critérios anteriormente propostos não puderam ser tratados devido à inacessibilidade aos dados para esses parâmetros.

Desta forma, o objetivo deste trabalho é realizar um estudo preliminar visando realizar um primeiro passo no sentido de validar as seguintes hipóteses ligadas às cadeias de suprimentos ágeis:

- Hipótese 1: Deve-se privilegiar tecnologias do tipo exclusivas (especializadas) em cadeias ágeis, o que favoreceria melhor uso de equipamentos em termos ambientais.

- Hipótese 2: A capacidade deve ser preferencialmente ociosa em cadeias ágeis, mas isso gera um custo ambiental relacionado a emissões de GEE e consumo de energia.

- Hipótese 3: A economia de escala (estrutura da rede) é um elemento classificado como 'aberto', necessitando ser analisado em cada situação. Nesse caso, a economia de escala é somente um "ponto de atenção’ que necessita ser adequadamente gerido, pois em algumas situações a estrutura da rede pode afetar a performance ambiental negativamente.

Os resultados apresentados a seguir permitem analisar essas três hipóteses em detalhes.

\subsection{Definições experimentais}

A cadeia de suprimentos estudada foi composta por um vetor- $n$ de parâmetros controláveis, $\theta$, bem como um vetor- $m$ de parâmetros não controláveis, $\xi$.

0 desempenho da cadeia de suprimentos pode ser expressa por $V_{\text {cs }}(\theta, \xi)$. Como $V_{\text {cs }}(\theta, \xi)$ depende de $\theta$ e $\xi$, visando otimizar o sistema é preciso encontrar o $\arg \max V_{\text {sc }}(\theta, \xi)$. Assim, esta experiência de simulação tem como objetivo identificar o melhor $\theta$, identificado como $\theta^{*}$ em (1):

$V_{\mathrm{sc}}\left(\theta^{*}, \xi\right)=\arg \max V_{\mathrm{sc}}(\theta, \xi)$

Os fatores controláveis foram definidos como $\theta=\{c, t, e\}$, em que,

- $c \in\{70 \%, 60 \%, 50 \%, 40 \%\}$ representa o nível de capacidade utilizada. Com base nisso, as capacidades ociosas seriam respectivamente de 30\%, $40 \%, 50 \%$ e $60 \%$;

- $t \in\{$ linhas polivalentes, linhas exclusivas $\}$ a tecnologia sendo empregada;

- e $\in$ \{centralizada, distribuída\} representa a estrutura da rede, o que está ligado fortemente à economia de escala sendo empregada.

Para tanto, tem-se três fatores controláveis. Dois deles possuem níveis duplos e um possui quatro níveis. Pressupondo-se que dois desses fatores podem interagir entre si, foram testadas interações de primeira ordem do tipo $t \times$ e e do tipo $c \times t$. Quando tais interações se confirmam, o efeito de um fator depende do nível de outros fatores. Pelo fato de não se acreditar na interação cx e, esta não foi analisada neste trabalho, reduzindo grandemente a quantidade de experimentos necessários.

Apesar dos fatores de ruído não serem controlados pelos gestores no mundo real, em um experimento de simulação isso pode ser realizado com relativa facilidade. De acordo com Davis (1993), uma cadeia de suprimentos é afetada normalmente por três tipos de incertezas, a saber: abastecimento, processo de produção e demanda. Ao testar essas incertezas, é possível determinar o melhor ajuste dos fatores controláveis para minimizar os impactos negativos dos fatores não controláveis sobre o desempenho da cadeia. Em função dos dados disponibilizados pela empresa, optou-se por incluir na análise somente a demanda e o processo de produção.

Desta maneira, as incertezas (ou fatores não controláveis) consideradas neste experimento foram definidas como $\xi=\{m, d\}$, em que:

- $m \in\{$ baixa perturbação, alta perturbação\} representa as incertezas de fabricação, sendo que em situações de baixa perturbação, 90\% da capacidade está disponível para a produção; e, em situações de alta perturbação, somente $80 \%$ da capacidade está disponível, devido a problemas no chão de fábrica, como quebra de máquinas e absenteísmo;

- $d \in\{$ demanda otimista, demanda pessimista representa a incerteza da demanda. A demanda otimista representa $115 \%$ das previsões, enquanto 
que a pessimista representa $85 \%$ das previsões de demanda.

Assim, os experimentos contiveram dois fatores de ruído em dois níveis cada. É importante salientar que $m$ e $d$ são incertezas determinísticas, ou seja, não foram geradas variáveis aleatórias nesses experimentos, mas foram testados cenários com diferentes níveis de incertezas a fim de se analisar a robustez do sistema.

Finalmente, para avaliar o comportamento de resposta dos experimentos, foram definidos dois KPls (Key Performance Indicators): emissões de Gás de Efeito Estufa (GEE) e custo de fabricação (C), que são calculados conforme as Equações 2 e 3 a seguir:

$$
\begin{aligned}
& G E E(\text { ton } C O 2)= \\
& \sum_{p \in \text { produtos acabados }}\left(\begin{array}{l}
\text { emissões transporte interno } \\
\text { emissões transporte externo } \\
\text { em }_{p}
\end{array}\right)
\end{aligned}
$$

$$
\left.\begin{array}{l}
C(R \$)= \\
\sum_{p \in \text { produtos acabados }}\left(\begin{array}{l}
\text { custos fabricação }_{p}+\text { custos estoque }_{p}+ \\
\text { custos distribuição }
\end{array}\right.
\end{array}\right)
$$

A partir das definições experimentais, foi realizado o delineamento experimental utilizando matrizes ortogonais (Taguchi, 1986). Taguchi desenvolveu matrizes ortogonais, gráficos e tabelas lineares triangulares para fornecer o máximo de informação com a menor quantidade de ensaios. Usando a lógica de Taguchi de matrizes ortogonais, foi selecionado o projeto $L_{16}$ para os fatores controláveis. Esta matriz ortogonal é útil para até 15 fatores controláveis e pode também ser usada para capturar as interações. Foi utilizada uma abordagem mista para tratar os níveis, uma vez que dois fatores têm dois níveis possiveis, e um fator pode assumir quatro níveis. Seria possivel utilizar uma matriz interna mais rentável (por exemplo, a $L_{8}$ ), mas isso limitaria o estudo em termos de análise de interações. Como há interesse em se compreender as interações entre os fatores, a $L_{16}$ caracteriza-se como uma boa alternativa. Quanto à matriz externa, foi utilizada a $L_{4}$, que é indicada para até três fatores a dois níveis. A matriz externa orientará a definição de quatro repetições. 0 número total de experimentos foi 64 , ou seja, 16 cenários e 4 repetições.

É interessante lembrar que, no método Taguchi, a matriz interna $L_{16}$ fornece a combinação dos fatores controláveis, enquanto a matriz externa $L_{4}$ indica como configurar os fatores não controláveis com a finalidade de estabelecer-se replicações lógicas. Assim, os experimentos realizados seguiram as configurações indicadas na Tabela 1a e na Tabela $1 \mathrm{~b}$.
Os valores 1, 2, 3 e 4 indicam os níveis de cada fator. Por exemplo, a tecnologia pode ser 1 (polivalente), ou 2 (especializada); a capacidade possui níveis variando de 1 a 4, sendo 1 a totalmente plena e 4 a totalmente ociosa, e os valores 2 e 3 sendo intermediários; já a estrutura da rede (economia de escala) varia de 1 (centralizada) a 2 (distribuída); a demanda de 1 (pessimista) a 2 (otimista) e a Fabricação de 1 (baixa perturbação) a 2 (alta perturbação).

\subsection{Coleta de dados e simulações}

A coleta de dados se realizou durante vários meses, e a equipe contou com a ajuda de diversos funcionários da empresa, pois a quantidade e complexidade exigia a participação de especialistas do negócio. Os dados coletados foram, principalmente, relacionados a:

- Rede logística: dados sobre geoposicionamento (latitude e longitude) de todos os nós da rede logística da empresa, especialmente fornecedores, plantas, armazéns, centros de distribuição e clientes.

- Modais: tipos de modais de transporte, especialmente rodoviário e marítimo, capacidade da frota e o consumo médio de combustíveis de cada modal por quilômetro percorrido.

- Produtos: informações sobre tamanho e peso de todas as famílias de produtos da empresa, cuja ordem de grandeza estava na casa de centenas de famílias. Também, obtiveram-se dados sobre a

Tabela 1. Plano de experimentos L16 e L4 aplicável à GEE e C. a) Matriz Interna L16.

\begin{tabular}{cccc}
\hline Experimento & $\begin{array}{c}\text { Tecnologia } \\
(\text { T) }\end{array}$ & $\begin{array}{c}\text { Capacidade } \\
(\mathrm{C})\end{array}$ & $\begin{array}{c}\text { Estrutura Rede } \\
(\mathrm{E})\end{array}$ \\
\hline 1 & 1 & 1 & 1 \\
2 & 1 & 1 & 2 \\
3 & 1 & 2 & 1 \\
4 & 1 & 2 & 2 \\
5 & 1 & 3 & 1 \\
6 & 1 & 3 & 2 \\
7 & 1 & 4 & 1 \\
8 & 1 & 4 & 2 \\
9 & 2 & 1 & 1 \\
10 & 2 & 1 & 2 \\
11 & 2 & 2 & 1 \\
12 & 2 & 2 & 2 \\
13 & 2 & 3 & 1 \\
14 & 2 & 3 & 2 \\
15 & 2 & 4 & 1 \\
16 & 2 & 4 & 2 \\
\hline
\end{tabular}

\begin{tabular}{lllll} 
b) Matriz Externa L4 para replicações. \\
\hline Demanda (D) & 1 & 2 & 1 & 2 \\
Fabricação (M) & 1 & 2 & 2 & 1 \\
\hline
\end{tabular}


bill-of-material dos produtos visando identificar a dependência técnica de componentes produzidos em diferentes plantas e/ou por diferentes fornecedores.

- Produção: informações sobre as linhas de produção (capabilidade dos processos, capacidade em termos de volumes, consumo médio de energia, dentre outras informações).

- Mercado: definições de alocação de produtos aos diferentes mercados regionais servidos pela empresa.

- Demanda: histórico e projeções futuras de demanda para todas as famílias de produtos da empresa.

- Estoques: informações sobre capacidade dos armazéns e dos centros de distribuição, bem como quais são as políticas de gestão de inventário da empresa.

É importante salientar que os dados fornecidos pela empresa foram compilados pela equipe e utilizados para a parametrização de um "sistema de otimização de redes logísticas” (Martel \& Vieira, 2008) canadense chamado Supply Chain Studio ${ }^{\circledR}$ (Modellium, 2012). 0 modelo resultante representa o Status-Quo da cadeia de suprimentos, contendo todos os nós e arcos da cadeia em estudo.

Visando estudar possíveis variações futuras do Status Quo, a equipe consultou a diretoria da empresa sobre as projeções futuras no que tange a novos nós na rede, novas tecnologias, aquisição de novas capacidades e novos mercados. Esses dados, bem como as previsões de demanda futura para os próximos anos, foram adicionados ao sistema. Com base nessas novas informações, o sistema é capaz de propor uma nova configuração da rede que minimize, por exemplo, custos e emissões, para a janela temporal escolhida. Para o caso do presente estudo, a janela temporal foi de dez anos.

Os indicadores de desempenho $(\mathrm{KPI})$ representam somatórios de custos e emissões decorrentes da fabricação dos produtos projetados para os próximos dez anos. Para o cálculo dos custos, foram levados em consideração basicamente custos de fabricação, custos de estocagem e custos de transporte. Os transportes são de extrema importância para a empresa, dado que ela serve praticamente toda a América Latina. Assim, o cálculo dos custos e das emissões de transporte foram realizados com base no volume de mercadorias transportado, nas distâncias percorridas, no consumo de combustível médio da frota da empresa e nos fatores de conversão de combustíveis (para o caso das emissões de $\mathrm{CO}_{2}$ ). Considerou-se tanto o transporte terrestre, unicamente rodoviário, quanto o transporte marítimo. Cabe notar que não foram utilizados outros tipos de emissões (e.g. as oriundas do processo produtivo) por indisponibilidade de dados no momento do estudo.

A partir dessas configurações básicas do sistema, os cenários propostos pelas matrizes ortogonais da Tabela 2 foram configurados com diferentes combinações em termos de demanda (D), capacidade (M), tecnologia (T), capacidade usada para PCP (C) e estrutura de redes (E). Essas variáveis eram configuradas diretamente no sistema, sendo fixadas para toda a janela temporal de dez anos. Por

Tabela 2. Resultados para o plano de experimentos em termos de emissões e custos.

\begin{tabular}{|c|c|c|c|c|c|c|c|c|c|c|c|}
\hline & & & \multirow{2}{*}{$\frac{\text { Replicação }}{\text { D }}$} & \multicolumn{4}{|c|}{ GEE (Tons de C02) } & \multicolumn{4}{|c|}{ Custos (milhões R\$) } \\
\hline & & & & 1 & 2 & 1 & 2 & 1 & 2 & 1 & 2 \\
\hline & & & M & 1 & 2 & 2 & 1 & 1 & 2 & 2 & 1 \\
\hline Experimento & $\mathrm{T}$ & C & $\mathrm{E}$ & & & & & & & & \\
\hline 1 & 1 & 1 & 1 & 4266,73 & 5772,63 & 4266,73 & 5772,63 & 325,71 & 477,71 & 360,46 & 432,11 \\
\hline 2 & 1 & 1 & 2 & 4659,82 & 6304,45 & 4659,82 & 6304,45 & 325,71 & 477,71 & 360,46 & 432,11 \\
\hline 3 & 1 & 2 & 1 & 4453,87 & 6025,82 & 4453,87 & 6025,82 & 378,53 & 553,07 & 412,53 & 500,93 \\
\hline 4 & 1 & 2 & 2 & 4864,20 & 6580,96 & 4864,20 & 6580,96 & 378,53 & 553,07 & 412,53 & 500,93 \\
\hline 5 & 1 & 3 & 1 & 4715,86 & 6380,28 & 4715,86 & 6380,28 & 439,20 & 657,60 & 487,20 & 590,40 \\
\hline 6 & 1 & 3 & 2 & 5150,32 & 6968,08 & 5150,32 & 6968,08 & 439,20 & 657,60 & 487,20 & 590,40 \\
\hline 7 & 1 & 4 & 1 & 5108,85 & 6911,97 & 5108,85 & 6911,97 & 548,60 & 806,00 & 600,60 & 728,00 \\
\hline 8 & 1 & 4 & 2 & 5579,52 & 7548,75 & 5579,52 & 7548,75 & 548,60 & 806,00 & 600,60 & 728,00 \\
\hline 9 & 2 & 1 & 1 & 4266,73 & 5772,63 & 4266,73 & 5772,63 & 351,77 & 497,26 & 377,83 & 453,83 \\
\hline 10 & 2 & 1 & 2 & 4659,82 & 6304,45 & 4659,82 & 6304,45 & 351,77 & 497,26 & 377,83 & 453,83 \\
\hline 11 & 2 & 2 & 1 & 4453,87 & 6025,82 & 4453,87 & 6025,82 & 401,20 & 578,00 & 444,27 & 521,33 \\
\hline 12 & 2 & 2 & 2 & 4864,20 & 6580,96 & 4864,20 & 6580,96 & 401,20 & 578,00 & 444,27 & 521,33 \\
\hline 13 & 2 & 3 & 1 & 4715,86 & 6380,28 & 4715,86 & 6380,28 & 472,80 & 676,80 & 508,80 & 621,60 \\
\hline 14 & 2 & 3 & 2 & 5150,32 & 6968,08 & 5150,32 & 6968,08 & 472,80 & 676,80 & 508,80 & 621,60 \\
\hline 15 & 2 & 4 & 1 & 5108,85 & 6911,97 & 5108,85 & 6911,97 & 566,80 & 832,00 & 624,00 & 751,40 \\
\hline 16 & 2 & 4 & 2 & 5579,52 & 7548,75 & 5579,52 & 7548,75 & 566,80 & 832,00 & 624,00 & 751,40 \\
\hline
\end{tabular}

Em que: demanda (D), capacidade (M), tecnologia (T), capacidade usada para PCP (C), estrutura de redes (E). 
exemplo, na primeira rodada experimental (em que os três fatores controláveis estão em seus níveis mais baixos), ativou-se no sistema a tecnologia "polivalentes", a capacidade "70\%" e a estrutura de rede "centralizada". Também foram configurados os fatores não controláveis D e M para cada replicação, sendo a primeira demanda "otimista" e fabricação com "baixa perturbação". Sendo assim, para cada combinação dessa matriz, o sistema foi executado com o objetivo de produzir valores para as variáveis de resposta em termos de custos e de emissões. Os resultados das simulações para ambas as variáveis estão representados na Tabela 2.

Cabe notar que foi aplicado um fator de conversão aos dados da Tabela 2 por questões de confidencialidade, exigidos pela empresa parceira. No entanto, a proporcionalidade dos dados não foi afetada, não comprometendo as análises estatísticas via a abordagem de Taguchi.

\subsection{Análise estatística}

Conforme mencionado, foram executados 64 experimentos a fim de se compreender o desempenho do sistema quanto aos indicadores $G E E_{\mathrm{ij}}$ e $C_{\mathrm{ij}}$ ( $i$ representa o cenário/experimento e $j$ a replicação). Para análise dos dados, foi empregada a relação sinal-ruído (ou signal-to-noise, $S M$ ), conforme proposto pelo método Taguchi. 0 sinal representa um valor médio de respostas e de correspondência para o componente desejado. 0 ruído é uma medida da variabilidade e representa os componentes indesejáveis. A maior relação $S N$, medida em $\mathrm{dB}$, oferece a melhor situação para $\mathrm{o}$ indicador de desempenho analisado. Desta forma, um $S N$ elevado indica que o alvo (sinal) é respeitado com uma dispersão reduzida do ruído.

A relação $S N$ foi aplicada buscando a minimização dos indicadores $G E E_{\mathrm{ij}}$ e $C_{\mathrm{ij}}$. Para tanto, a abordagem de Taguchi recomendada foi a "smaller-is-better" (Taguchi, 1986), calculada conforme as equações 4 e 5 , a seguir.

$$
\begin{aligned}
& S N_{i}\left(G H G_{i}\right)=-10 \cdot \log _{10}\left(\frac{1}{N_{i}} \sum_{j=1}^{N_{i}} G H G_{i, j}^{2}\right) \\
& S N_{i}\left(C_{i}\right)=-10 \cdot \log _{10}\left(\frac{1}{N_{i}} \sum_{j=1}^{N_{i}} C_{i, j}^{2}\right)
\end{aligned}
$$

Em que $i$ é o número da experiência, $j$ a replicação e $N_{i}$ o número de replicações realizadas $\{a, b, c, d\}$.

A análise, segundo Taguchi, foi dividida em duas etapas primordiais:

- Etapa 1: Análise de variância - ANOVA após o processamento do $S N$ : permite determinar quais fatores são importantes, se existem interações de primeira ordem entre eles e se tais interações são relevantes;

- Etapa 2: Gráficos de SN: determinam a melhor configuração do sistema, ou seja, a que maximiza a performance dos indicadores de desempenho face às incertezas dos experimentos realizados. Outra possibilidade é avaliar os trade-offs entre os fatores estudados em função das hipóteses lançadas.

Neste estudo, ambas as etapas foram realizadas com a ajuda do sistema especialista Optimum $^{\circledR}$. As seções seguintes explicam como cada etapa foi realizada.

\subsubsection{ANOVA}

Taguchi (1986) propõe a utilização de uma abordagem ANOVA-modificada. Essas análises para os experimentos são apresentadas na Tabela $3 \mathrm{e}$ na Tabela 4, respectivamente para o $G E E_{\mathrm{ij}}$ e o $C_{\mathrm{ij}}$. A versão adaptada da ANOVA pode ser interpretada da seguinte forma: a coluna Contribuição indica o percentual de influência do fator sobre a variação do KPl; a coluna Probabilidade de F índica o percentual de confiança da contribuição; a coluna Pooling indica os fatores que possuem influências negligenciáveis e que foram agregados ao Erro; finalmente, o Erro indica o percentual de variação do KPI que não pode ser explicado pelo experimento.

Tabela 3. ANOVA para o GEEij.

\begin{tabular}{llccc}
\hline \multicolumn{1}{c}{ Fatores controláveis e interações } & Contribuição (\%) & Probabilidade de F (\%) & $\mathrm{F}$ & Pooling $^{*}$ \\
\hline 1 & Tecnologia & & $\mathrm{X}$ & $\mathrm{X}$ \\
2 & Capacidade & & & $\mathrm{X}$ \\
3 & Tecnologia X Capacidade & 97,6 & $\mathrm{X}$ \\
4 & Economia de Escala & & \\
5 & Tecnologia X Economia de Escala & 6,4 & & \\
$\quad$ Erro & 93,6 & & \\
\hline
\end{tabular}

${ }^{*}$ Como a contribuição de alguns fatores e interações eram muito pequenos, foi aplicada a técnica de pooling de forma que essa contribuição fosse inclusa no erro dos experimentos. Fonte: Dados da pesquisa. 
Maiores detalhes da abordagem ANOVA-modificada podem ser encontrados em Taguchi (1986).

A partir da Tabela 3, pode-se observar que a economia de escala é o único fator que afeta as emissões de GEE, possuindo ainda uma elevada probabilidade de $\mathrm{F}(97,6 \%)$. Isso é coerente com o tipo de experiência sendo realizada com relação ao GEE, pois somente os transportes internos e externos foram utilizados para o cálculo das emissões, já que as emissões de fabricação não foram levadas em consideração. Assumiu-se que, em cenários distribuídos, os mesmos equipamentos seriam utilizados, mas em localizações diferentes. Essa primeira análise apenas indica que a economia de escala possui relevância na análise.

Com base nesses experimentos, não foi possível determinar se os demais fatores são relevantes (i.e., estrutura da rede e as interações de primeira ordem). A Tabela 3 também indica que os fatores estudados não explicam cerca de $93,6 \%$ da variação das emissões de GEE. As razões para esse fenômeno serão explicadas a seguir.

Com relação à Tabela 4, observa-se que apenas dois fatores (a capacidade e a tecnologia) influenciam os custos, sendo confirmado com uma elevada probabilidade (Como $F$ da tecnologia é maior que 1 , isso significa que existe uma elevada chance de a tecnologia ser significativa) de $F$. Constata-se também que os experimentos não permitem detectar interações entre os fatores testados.

Ainda explorando a Tabela 4, observa-se que a tecnologia influencia somente $0,4 \%$ dos custos, enquanto a capacidade influencia $36,8 \%$ da variação dos custos. Juntos, eles podem influenciar quase $2 / 5$ dos resultados. Além disso, é importante observar que a ANOVA para os custos não pode explicar cerca de $68,9 \%$ da variação desse indicador.

0 fato de ambas as análises ANOVA não serem capazes de explicar uma parte considerável das variações dos indicadores selecionados está relacionado, possivelmente, à existência de outros fatores que os influenciam. No entanto, uma explicação complementar é possível: como os experimentos realizados são fortemente influenciados pelas variabilidades relacionadas à demanda e às incertezas do chão de fábrica (tal como descrito anteriormente), pode-se presumir que esses fatores não controláveis estão, em grande parte, correlacionados aos dois indicadores selecionados, influenciando fortemente a performance do sistema.

Apesar dos erros observados nas análises de variância, uma consideração importante pode ser enfatizada: os três fatores estudados podem ser usados para influenciar os custos e as variações de emissões e custos de uma empresa, principalmente a capacidade e as economias de escala.

Porém, uma questão emergiu desta conclusão parcial: Qual a configuração ideal desses fatores e quais são os trade-offs existentes? Para respondê-la, foi necessário estudar os gráficos de $S N$ de Taguchi, a etapa 2 do método.

\subsubsection{Gráficos de $S N$}

É importante salientar que os gráficos de $S N$ são utilizados para determinar a melhor combinação de fatores para se obter um sistema robusto. Desta forma, o foco do estudo foi avaliar qual seria a configuração mais estável em relação às variações do sistema. Para uma cadeia de suprimentos “ágil”, como é o caso da cadeia estudada, fez-se necessário identificar uma combinação de fatores que oferecesse um bom serviço sem, no entanto, comprometer as metas de custos da empresa em um contexto de variações constantes, principalmente de demanda. Tal como discutido anteriormente, a demanda é um fator importante nesse tipo de cadeias. No caso do presente estudo, cabe lembrar que o cenário da demanda variou $20 \%$ para cada ano, do horizonte total avaliado.

Nesse sentido, buscando estudar a melhor configuração desse sistema, os gráficos de $S N$ da Figura 5 oferecem informações relevantes.

Tabela 4. ANOVA para o Cij.

\begin{tabular}{|c|c|c|c|c|c|}
\hline & Fatores controláveis e interações & Contribuição (\%) & Probabilidade de $\mathrm{F}(\%)$ & $\mathrm{F}$ & Pooling* \\
\hline 1 & Tecnologia & 0,4 & 75,2 & 1,4 & \\
\hline 2 & Capacidade & 36,8 & 100,0 & 13,3 & \\
\hline 3 & Tecnologia X Capacidade & & & & $x$ \\
\hline 4 & Economia de Escala & & & & $x$ \\
\hline 5 & Tecnologia X Economia de Escala & & & & $x$ \\
\hline & Erro & 68,9 & & & \\
\hline
\end{tabular}

${ }^{*}$ Como a contribuicão de alguns fatores e interações eram muito pequenos, foi aplicada a técnica de pooling de forma que essa contribuição fosse inclusa no erro dos experimentos. Fonte: Dados da pesquisa. 


\section{Hipótese 1}

A partir da Figura 5, pode-se observar que, pelo fato do indicador de custo no primeiro gráfico possuir apenas uma leve inclinação, a tecnologia possui pouca capacidade de influenciar os resultados em termos práticos. A pequena inclinação pode oferecer apenas alguns indícios preliminares de como configurar o sistema para obter uma cadeia de suprimentos eficiente. Como a abordagem Taguchi propõe que se deve sempre maximizar a relação $S N$ para obter-se uma performance mais elevada, a tecnologia 2 (i.e., especializada) deveria ser privilegiada (mesmo que minimamente) visando obter um sistema robusto em termos de custos.

Isso está relacionado à hipótese 1 descrita anteriormente, a qual indica que tecnologias especializadas devem, muitas vezes, ser privilegiadas em cadeias ágeis. Segundo o modelo teórico proposto, em muitos casos, cadeias ágeis fazem uso de tecnologias especializadas para favorecer volumes do sistema produtivo, por exemplo, a Zara, que produz em larga escala roupas similares por um período longo para atender à demanda de uma estação. Como é sabido, tecnologias especializadas são normalmente associadas a maiores eficiências energéticas (Araújo \& Oliveira, 2010), sendo assim a "não existência" de trade-off para esse critério parece ser confirmada, mesmo que o gráfico de $S N$ para GEE tenha curva horizontal (i.e., esse fator não influencia a performance de emissões para a empresa estudada).

No entanto, importante se faz ressaltar que a tecnologia não é crítica em termos de custos, dado que a inclinação da curva do gráfico de $S N$ é de baixa intensidade. Isso significa que uma cadeia ágil também pode fazer uso de sistemas produtivos polivalentes, sem, no entanto, prejudicar enormemente o critério custo. Isso pode ocorrer em situações em que a empresa necessite de mais flexibilidade do sistema para absorver variações de demanda, por exemplo. Nesse caso, um trade-off ambiental pode existir, já que tecnologias polivalentes tendem a ser, em geral, menos eficientes (Araújo \& Oliveira, 2010) em termos energéticos, prejudicando assim as emissões.

Dessa forma, pode-se afirmar que os experimentos realizados colaboram em parte para confirmar a hipótese 1.

\section{Hipótese 2}

A hipótese 2 postula que "a capacidade deve ser preferencialmente ociosa em cadeias ágeis, mas isso gera um custo ambiental relacionado a emissões de GEE e consumo de energia".

Visando testar essa hipótese, o gráfico do meio na Figura 5 indica que, para atender a mercados ágeis, deve-se favorecer posições à direita no gráfico, ou seja, o máximo possível de capacidade extra visando absorver flutuações relacionadas à demanda, por exemplo. Isso é coerente com o modelo teórico proposto, o qual sugere que capacidades ociosas são importantes em cadeias ágeis.

No entanto, os gráficos de $S N$ não oferecem nenhuma informação no que tange ao trade-off com relação aos GEE, pois a capacidade não possui influência nas emissões do sistema estudado. Todavia, a literatura informa que equipamentos manufatureiros ociosos consomem energia de fundo quando estão em estado de standby (Araújo \& Oliveira, 2012). Como a energia está intimamente relacionada às emissões de GEE (STROKES, 2009), pode-se presumir que os experimentos realizados colaboram, parcialmente, para confirmar a hipótese 2 .

\section{Hipótese 3}

A hipótese 3 afirma que "a economia de escala (estrutura da rede) é um elemento classificado como 'aberto', necessitando ser analisado em cada situação. Nesse caso, a economia de escala é somente um 'ponto de atenção' que necessita ser

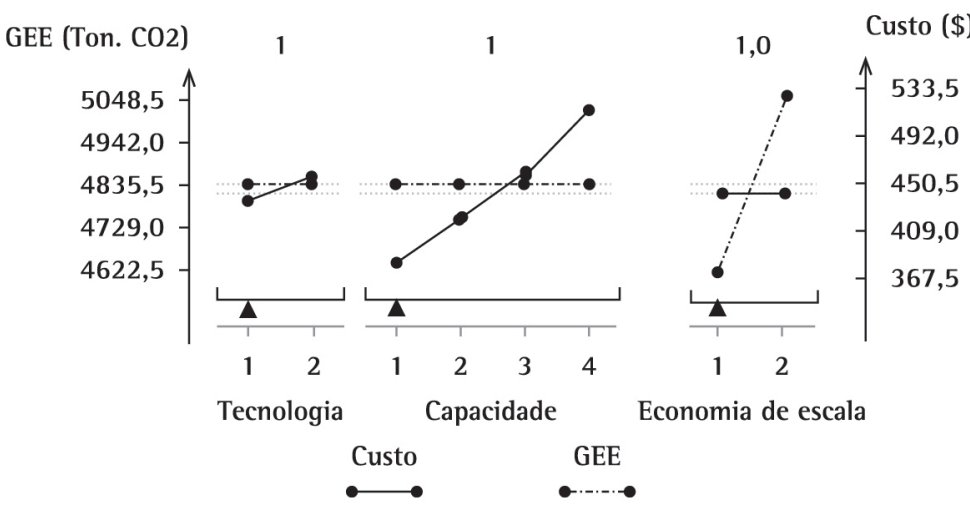

Figura 5. Gráfico de SN para emissões de GEE e custos. Fonte: Dados da pesquisa. 
adequadamente gerido, pois em algumas situações a estrutura da rede pode afetar a performance ambiental negativamente."

Conforme ilustrado pelo terceiro gráfico (na direita) de SN da Figura 5, os experimentos realizados evidenciam que mudanças no modelo de economia de escala (estrutura de rede centralizada versus distribuída) não influenciam os custos, mas afetam, em parte, as emissões $(6,4 \%$ das variações totais em termos de custos, segundo a ANOVA). Conforme indicado nesse gráfico, a estrutura distribuída deve ser favorecida (lado direito), pois esta maximiza a relação sinal/ruído.

Isso ajuda a corroborar, ao menos em parte, a hipótese 3, pois a característica 'aberta' realmente ocorre em relação aos custos, mas a economia de escala deveria ser gerenciada criteriosamente, pois poderia impactar significativamente as emissões de GEE.

Os experimentos indicam que provavelmente esse fator seja o mais importante em termos de emissões. Desta forma, foi realizado um estudo complementar que auxiliasse compreender qual a magnitude das reduções de GEE, no caso da escolha de uma estrutura distribuída.

Nesse sentido, a Figura 6 compara as emissões de GEE para quatro cenários de simulação utilizando dados reais da empresa estudada, a saber: i) Status Quo: representando a situação centralizada atual, em que apenas uma grande planta é utilizada para atender a todo o mercado mundial; ii) Distribuído 1: duas plantas menores são localizadas em pontos estratégicos do mercado consumidor e fornecedor; iii) Distribuído 2: três plantas diferentes, ainda menores, servem todos os mercados; iv) Distribuído 3: quatro plantas pequenas e distribuídas são empregadas. É interessante notar que o cenário centralizado representa o verdadeiro status quo da empresa, enquanto o cenário distribuído representa situações futuras possíveis para a empresa em que as novas plantas seriam estrategicamente localizadas próximas aos maiores mercados consumidores.

$\mathrm{Na}$ Figura 6, as simulações foram realizadas para os dez anos subsequentes à data de coleta dos dados deste estudo, sendo que o Ano 0 representa o momento atual e o Ano 4 o momento escolhido pela empresa para implementar a descentralização. As emissões de GEE foram determinadas utilizando-se da mesma abordagem de cálculo empregada precedentemente, ou seja, a fórmula de cálculo do indicador de desempenho GEE levou em conta as emissões dos transportes internos e externos da empresa, mas não as emissões de fabricação. Nesse caso, considerou-se que a empresa estaria usando, nos diferentes cenários, exatamente os mesmos equipamentos industriais para a fabricação, mas localizados em regiões distintas em cada cenário.

A partir do Ano 5, observa-se uma descontinuidade em relação ao cenário centralizado. De forma geral, no médio prazo, as emissões de GEE tendem a ser significativamente inferiores nos cenários distribuídos. Quanto mais distribuída a estrutura de rede, maiores são as reduções de emissões, pois provavelmente muito transporte de outbound seria evitado com plantas mais próximas aos mercados consumidores. Em média, as reduções são da ordem de $24 \%, 26 \%$ e $30 \%$ para os cenários distribuídos 1,2 e 3 respectivamente. Pode-se dizer que, nesses três casos, os ganhos são significativos.

Apesar de o critério economia de escala ter sido determinado como "aberto" e de não existir uma diretriz específica do modelo proposto para melhorar a performance econômica das empresas, as empresas devem gerenciá-lo de forma consciente, pois pode

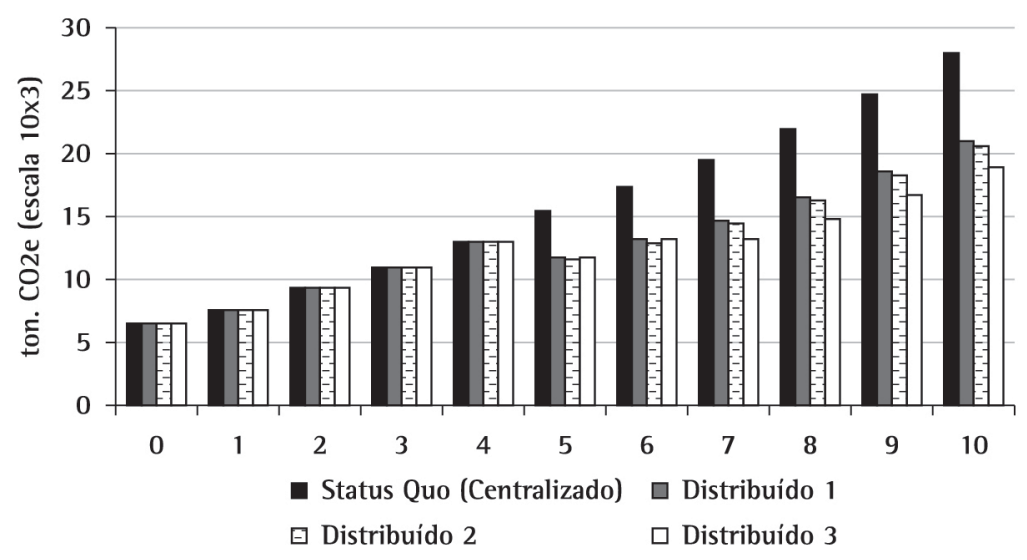

Figura 6. Emissões de GEE para quatro cenários de estrutura de rede da empresa estudada. Fonte: Dados da pesquisa. 
existir uma correlação entre ele e as emissões GEE. No caso estudado, evidenciou-se que, se possível, para a empresa em questão, deve-se privilegiar estruturas descentralizadas.

Segundo os experimentos realizados, pode-se acreditar que a situação ótima $\theta^{*}$ seria , confirmado pelo software Optimum ${ }^{\circledR}$ para os intervalos de confiança $e$, considerando-se um risco de rejeição de $5 \%$.

\section{Conclusões}

Este trabalho objetivou realizar um estudo exploratório para levantar indícios de potencial validade de parte de um quadro teórico inovador proposto por Santa-Eulalia e colegas, que combina princípios de projeto de cadeias de suprimentos com a teoria de alinhamento dinâmico de Gattorna (2006), a partir de uma perspectiva de gestão ambiental. Ao combinar esses conceitos, verifica-se que vários trade-offs ambientais podem existir ao se projetar diferentes cadeias de suprimentos visando atender clientes distintos.

Assim, o modelo proposto foi submetido a alguns testes experimentais em uma empresa de bens de consumo não duráveis, visando abordar algumas das hipóteses levantadas para cadeias de suprimentos ágeis. Os estudos preliminares quantitativos via Taguchi, somados às análises qualitativas realizadas, sugerem que as hipóteses relacionadas à economia de escala, à tecnologia e à capacidade possuem grande potencial de serem verdadeiras para o tipo de indústria estudado. Futuros estudos quantitativos deverão ser ainda realizados na mesma empresa e em outros tipos de indústrias, visando complementar esses testes preliminares, bem como testar outras hipóteses instrumentais levantadas no modelo teórico. Também, estudos mais amplos, que contemplem outros métodos estatísticos complementares serão realizados, especialmente surveys com aplicação de equações estruturais. Novos insights surgirão e novas versões desse quadro conceitual serão publicadas futuramente.

\section{Referências}

Albuquerque, G. M., Fleury, M. T. L., \& Fleury, A. L. (2011). Vertical integration in service industries: an exploratory study at the healthcare industry in São Paulo. Produção, 21(1), 39-52.

Araújo, J. B., \& Oliveira, J. F. G. (2012). Towards a balanced scoreboard for assessing manufacturing processes. International Journal of Business Performance Management, 13(2), 198-221. http://dx.doi.org/10.1504/ IJBPM.2012.046201.
Baglin, G., Bruel, O., Garreau, A., Greif, M., Kerbache, L., \& Delft, C. V. (2007). Management industriel et logistique: concevoir et piloter la supply chain. Paris: Economica.

Bryman, A. (1989). Research methods and organization studies. London: Unwin Hyman.

Carbon Disclosure Project - CDP. (2011). CDP Supply Chain Initiative. Recuperado em 13 de julho de 2011, de www. cdproject.net.

Davis, T. (1993). Effective supply chain management. Sloan Management Review, 3(4), 35-46.

Dias, S. L. F., Labegalini, L., \& Csillag, M. (2012). Sustentabilidade e cadeia de suprimentos: uma perspectiva comparada de publicações nacionais e internacionais. Produção, 22(13), 517-533.

Elkington, J. (1998). Cannibals with forks: he triple bottom line of 21 st century business. Environmental Quality Management, 8(1), 37-51.

Gattorna, J. (2006). Living supply chains: how to mobilize the enterprise around delivering what your customer want. London: FT Prentice.

Gattorna, J. (2009). Living supply chains: alinhamento dinâmico de cadeias de valor. São Paulo: Prentice Hall.

Genin, P., Thomas, A., \& Lamouri, S. (2007). How to manage robust tactical planning with an APS (Advanced Planning Systems). Journal of Intelligent Manufacturing, 18(2), 209-222. http://dx.doi.org/10.1007/s10845-0070015-y.

Gupta, A., \& Maranas, C. D. (2003). Managing demand uncertainty in supply chain planning. Computers \& Chemical Engineering, 27(8-9), 1219-1227. http:// dx.doi.org/10.1016/S0098-1354(03)00048-6.

Hervani, A., Helms, M. M., \& Sarkis, J. (2005). Performance measurement for green supply chain management. Benchmarking: an International Journal, 12(4), 330-353. http://dx.doi.org/10.1108/14635770510609015.

Hutchins, M. J., \& Sutherland, J. W. (2008). An exploration of measures of social sustainability and their application to supply chain decisions. Journal of Cleaner Production, 16(15), 1688-1698. http://dx.doi.org/10.1016/j. jclepro.2008.06.001.

Kettani, 0. (2008). A DSS for the design of supply networks. In CORS/Optimization Days 2008 Joint Conference, Québec, Canadá.

Klibi, W., Martel, A., \& Guitouni, A. (2010). The design of robust value-creating supply chain networks: a critical review. European Journal of Operational Research, 203(2), 283-293. http://dx.doi.org/10.1016/j.ejor.2009.06.011.

Kotzab, H., Seuring, S., Muller, M., \& Reiner, G. (2005). Research methodologies in supply chain management. Copenhagen: Physica-Verlag.

Lakhal, S., Martel, A., Kettani, 0., \& Oral, M. (2001). On the optimization of supply chain networking decisions. European Journal of Operational Research, 129(2), 259-270. http://dx.doi.org/10.1016/S03772217(00)00223-X.

Martel, A., \& Vieira, D. R. (2008). Análise e projetos de redes logísticas. São Paulo: Saraiva.

Modellium. (2012). Empresa Modellium. Recuperado em 13 de julho de 2011, de www.modellium.com. 
Pacheco, R. F., \& Siqueira, L. Z. (2006). Solução simultânea de problemas logísticos de localização de depósitos e centralização de estoques. Produção, 16(3), 481-492.

Pagell, M., \& Zhaohui, W. (2009). Building a more complete theory of sustainable supply chain management using case studies from 10 exemplars. The Journal of Supply Chain Management, 45(2), 37-56. http://dx.doi. org/10.1111/j.1745-493X.2009.03162.x.

Santa-Eulalia, L. A., Araújo, J. B., Kettani, O., Franciosi, L. A., Azevedo, R. C., \& Bremer, C. F. (2009). An essay on green supply chain design and dynamic alignment (Working Paper CIRRELT-2009-53). Québec: Interuniversity Research Centre on Enterprise Networks, Logistics and Transportation.

Santa-Eulalia, L. A., Araújo, J. B., Kettani, O., Francioli, L. A., Azevedo, R. C., \& Bremer, C. F. (2010). An essay on green supply chain design and dynamic alignment. In 3rd International Conference on Information Systems, Logistics and Supply Chain: Creating Value Through Green Supply Chains, Casablanca, Morrocos.

Santa-Eulalia, L. A., Aït-Kadi, D., D’Amours, S., Frayret, J.M., \& Lemieux, S. (2011). Agent-based experimental investigations about the robustness of tactical planning and control policies in a softwood lumber supply chain. Production Planning and Control, 22(8), 782-799. http:// dx.doi.org/10.1080/09537287.2010.543561.

Seuring, S., \& Müller, M. (2008). From a literature review to a conceptual framework for sustainable supply chain management. Journal of Cleaner Production, 16(15), 1699-1710. http://dx.doi.org/10.1016/j. jclepro.2008.04.020.
Shang, J., Li, S., \& Tadikamalla, P. (2004). Operational design of a supply chain system using the Taguchi method, response surface methodology, simulation, and optimization. International Journal of Production Research, 42(18), 3823-3849. http://dx.doi.org/10.1080/ 00207540410001704050.

Silva, E. L., \& Meneses, E. M. (2005). Metodologia da pesquisa e elaboração de dissertação (4. ed.). Florianópolis: UFSC. $138 \mathrm{p}$.

Stokes, S. (2009). The age of carbon. AMR Research.

Svensson, G. (2007). Aspects of sustainable supply chain management: conceptual framework and empirical example. Supply Chain Management, 12(4), 262-266. http://dx.doi.org/10.1108/13598540710759781.

Taguchi, G. (1986). Introduction to quality engineering: designing quality into products and processes. New York: Quality Resources.

UN Global Compact. BSR. (2010). Supply Chain Sustainability: a practical guide for continuous improvement. Recuperado em 13 de julho de 2011, de http://www. unglobalcompact.org

Vernalha, H. B., \& Pires, S. R. 1. (2005). Um modelo de condução do processo de outsourcing e um estudo de caso na indústria de processamento químico. Produção, 15(2), 273-285.

Wilkerson, T. (2008). Introduction to GreenSCOR. In Supplychain World North America Conference \& Exposition, Minneapolis.

\title{
Design of agile and green supply chains: an exploratory study in a non-durable consumer company
}

\begin{abstract}
Emerging trends in the area of supply chain management are significantly impacting academia and the business environment. Among these trends are the dynamic alignment paradigm and the sustainable supply chain management approach. The dynamic alignment paradigm recognizes that companies should dynamically manage different types of supply chains (e.g., fully flexible, agile, lean, and continuous replenishment) to respond appropriately to various types of customers' behaviors. The sustainable supply chain management approach accounts for various environmental and social issues as complements to the traditional economic criteria in the design and management of these different types of supply chains. In a recent study, some authors combined these two trends in a novel conceptual model aiming to help decision-makers better manage different environmental trade-offs when designing a supply chain using the dynamic alignment concept. This study presents some experimental studies on the 'agile' supply chain to verify some of the assumptions made by the model. To do so, simulation experiments were conducted for a large multinational company producing non-durable consumer goods. The results provide evidence that the conceptual model proposed is consistent and has the potential to help companies design agile and green supply chains.
\end{abstract}

Keywords

Supply chains. Sustainability. Dynamic alignment. Logistics network design. Non-durable consumer goods industry. Taguchi experimental design. 